\title{
PENGELOLAAN MADU LALAU OLEH MASYARAKAT DESA NANGA LAUK KECAMATAN EMBALOH HILIR KABUPATEN KAPUAS HULU
}

\author{
Forest Honey Management by the Community in Nanga Lauk Village Embaloh District of \\ Kapuas Hulu Regency
}

\author{
Hariska, Iswan Dewantara, Muflihati
}

Fakultas Kehutanan Universitas Tanjungpura Jalan Imam Bonjol, Pontianak 78124

E-mail : hariska.riska12@gmail.com

\begin{abstract}
The management of forest honey in Nanga Lauk Village is still carried out modestly by the local community. The honeycomb tree is a tree that is tall, big, and sturdy with wide branches that bees naturally nest in. Forest honey belongs to the Apis dorsata forest bee which is the most productive honey bee in producing honey. This study aims to examine the way on how the management of forest honey in Nanga Lauk Village, Embaloh Hilir District, Kapuas Hulu Regency. A survey method with observation and interview techniques is employed in this study. Interviews were conducted with people who own the honeycomb trees. Respondents were selected using a census technique based on ownership of honeycomb trees. The data are obtained from respondents who own honeycomb trees with a total of 10 groups that have been studied. Based on the qualitative descriptive analysis, the Nanga Lauk Village community has carried out traditional honey management in groups for generations starting from forest area maintenance, forest honey harvesting, packaging, and marketing. From the results of the study, it can be concluded that the management of forest honey in Nanga Lauk Village still uses honeycomb trees which have been applied from generation to generation. This is one of the values to maintain and preserve the existence of forest honey bees in Nanga Lauk Village.
\end{abstract}

Keywords: forest honey, Nanga Lauk Village, ownership of honeycomb trees, honey processing

\begin{abstract}
Abstrak
Pengelolaan madu hutan di Desa Nanga Lauk masih dilakukan secara sederhana oleh masyarakat setempat. Pohon sarang lalau adalah pohon yang tinggi dan besar serta kokoh dan memiliki dahan lebar yang dihinggapi lebah untuk bersarang secara alami. Madu lalau berasal dari lebah hutan Apis dorsata yang merupakan lebah madu yang paling produktif dalam penghasil madu. Penelitian ini bertujuan untuk mengkaji bentuk pengelolaan madu hutan di Desa Nanga Lauk, Kecamatan Embalaoh Hilir, Kabupaten Kapuas Hulu. Penelitian ini menggunakan metode survey dengan teknik observasi dan wawancara. Wawancara dilakukan terhadap masyarakat yang memiliki pohon sarang lalau. Pemilihan responden dilakukan dengan menggunakan teknik sensus berdasarkan kepemilikan pohon sarang lalau. Penelitian ini memperoleh data dari responden yang memiliki pohon sarang madu sendiri dengan jumlah 10 kelompok yang telah diteliti. Berdasarkan analisis diskriptif kualitatif, pengelolaan madu lalau dilakukan oleh Masyarakat Desa Nanga Lauk secara tradisional, turun temurun dan berkelompok mulai dari pemeliharaan kawasan hutan, pemanenan madu hutan, pengemasan dan pemasaran. Dari hasil penelitian dapat disimpulkan bahwa pengelolaan madu hutan di Desa Nanga Lauk masih menggunakan pohon sarang lalau yang diterapkan secara turun-temurun. Hal ini merupakan salah satu nilai untuk mempertahankan dan melestarikan keberadaan lebah madu hutan yang ada di Desa Nanga Lauk.
\end{abstract}

Kata kunci : madu lalau, Desa Nanga Lauk, kepemilikan pohon sarang, pengolahan madu, pemasaran 


\section{PENDAHULUAN}

Madu hutan merupakan salah satu hasil hutan bukan kayu (HHBK) potensial yang menjadi komoditas unggulan dan memiliki nilai ekonomis dalam menunjung aktivitas perekonomian masyarakat, terutama masyarakat disekitar hutan. Kabupaten Kapuas Hulu merupakan salah satu daerah yang banyak menghasilkan madu hutan, salah satunya adalah madu lalau. Madu lalau adalah madu hutan yang dihasilkan dari lebah yang bersarang secara alami pada pohon besar dan tinggi yang memiliki dahan yang lebar dan kokoh. Keberlangsungan produksi madu lalau ditentukan oleh cara pengelolan madu yang dilakukan oleh masyarakat.

Pengelolaan madu hutan merupakan kegiatan yang dilakukan oleh sekelompok masyarakat sebagai upaya terhadap keberlangsungan produksi madu secara lestari. Pengelolaan madu hutan dimulai dari penentuan dan pemeliharaan kawasan hutan, proses pemanenan madu, pengemasan hingga pemasaran. Masyarakat Kaban Meliau Danau Sentarum menyebut kelompok yang mengelola madu sebagai petani madu. Mereka membagi kelompok berdasarkan kepemilikan pohon sarang. Proses pengelolaan madu hutan berlandaskan kearifan lokal yang dilakukan berdasarkan aturan yang telah ditetapkan oleh masingmasing kelompok (Sofia, 2017). Masyarakat Tunggul Boyok juga mengelola madu hutan berdasarkan kearifan lokal setempat, dengan menerapkan aturan dan larangan dalam proses pengelolaan madu (Micahel, 2015).
Desa Nanga Lauk Kabupaten Kapuas Hulu sudah sejak lama mengelola dan memanfaatkan madu hutan sebagai salah satu hasil hutan bukan kayu. Proses pengelolaan madu hutan masih dilakukan secara sederhana berlandaskan pada kebiasaan dan budaya setempat. Pengelolaan madu hutan di Desa Nanga Lauk menjadi penting di lakukan karena secara ekonomi sangat menguntungkan, selain itu masyarakat menganggap bahwa madu hutan merupakan warisan dari para leluhur yang harus dipertahankan keberadaannya. Masyarakat menyadari bahwa mereka sangat bergantung sepenuhnya terhadap hasil hutan sehingga pengelolaan madu hutan merupakan sesuatu yang mutlak bagi mereka. Penelitian ini dilakukan untuk mengkaji bentuk pengelolaan madu hutan di Desa Nanga Lauk Kecamatan Embalaoh Hilir Kabupaten Kapuas Hulu.

\section{METODE PENELITIAN}

Penelitian ini dilaksanakan pada musim panen madu yaitu bulan OktoberJanuari di Desa Nanga Lauk Kecamatan Embaloh Hilir Kabupaten Kapuas Hulu. Metode pengumpulan data menggunakan teknik wawancara, pengamatan dan mengikuti langsung kegiatan proses pengelolaan madu hutan. Wawancara dilakukan kepada responden yang memiliki pohon sarang madu lalau. Data disusun secara tabulasi dan dianalisis secara deskriptif kualitatif dari masing-masing tahapan pengelolaan yang diamati. Diskriptif kualitatif dilakukan untuk menggambarkan konsep kearifan lokal masyarakat. Analisa data yang diuraikan dalam bentuk narasi dihubungkan dengan 
hasil wawancara agar apa yang dilihat, didengar dan didapat dari masyarakat pengelolaan madu hutan yang ada di desa tersebut ( Nawawi 2005).

\section{HASIL DAN PEMBAHASAN}

Madu lalau berasal dari lebah hutan Apis dorsata atau disebut juga Muanyi', merupakan lebah madu yang paling produktif, penghasil madu dan malam lebah. Madu dari spesies ini dikenal sebagai madu alam atau madu hutan. Pengelolaan madu lalau yang dilakukan oleh Masyarakat Desa Nanga Lauk masih dilakukan secara tradisional, turun temurun dan berkelompok, yang dimulai dari pemeliharaan kawasan hutan, pemanenan madu hutan, pengemasan hingga pemasaran.

\section{Pemeliharaan Kawasan Hutan}

Kawasan hutan yang dijadikan tempat untuk memanen madu ditentukan berdasarkana keberadaan pohon sarang lalau. Masyarakar Desa Nanga Lauk dalam menjaga dan memelihara kawasan hutan, memiliki aturan yang tidak boleh dilanggar oleh masyarakat desa. Aturan tersebut adalah masyarakat dilarang menebang pohon sarang, tidak diperbolehkan membuka lahan perladangan di sekitar kawasan hutan dan melakukan pembersihan di sekitar dan pada pohon sarang. Berdasarkan hasil wawancara dengan petani madu, bahwa membuka lahan perladangan dengan sistem bakar dikhawatirkan dapat menyebabkan kebakaran hutan dan asap yang ditimbulkan membuat lebah tidak mau datang dan bersarang di pohon tersebut. Aturan ini dibuat agar kawasan hutan tetap terjaga dan tidak terjadi kerusakan yang disebabkan oleh manusia, sehingga produksi dan kualitas madu hutan tetap terjaga dan lestari. Menurut Julmansyah (2010) kelestarian hutan merupakan prasyarat bagi usaha madu hutan yang berkesinambungan, sehingga dalam pemilihan kawasan yang tepat untuk tempat bersarang lebah madu mengutamakan kawasan hutan yang masih bagus dan terhindar dari kerusakan.

\section{Penentuan Kepemilikan Pohon Sarang Lalau}

Penentuan kepemilikan pohon sarang lalau di Desa Nanga Lauk dilakukan berdasarkan beberapa aturan yang berlaku, antara lain (1) Kepemilikan pohon sarang lalau berdasarkan atas warisan dari generasi sebelumnya dan dapat diwariskan secara turun-temurun ke generasi selanjutnya (2) Pohon sarang lalau dapat berupa pemberian dari pihak keluarga untuk dikelola besamasama (3) Bagi pohon sarang yang baru ditemukan dan belum ada pemiliknya, maka penemu pertama pohon sarang tersebut dapat memberi tanda kepemilikan berupa inisial huruf di batang pohon menggunakan cat atau di kerik di batang pohon (4) Kepemilikan pohon sarang dimiliki oleh masing-masing kelompok, biasanya dalam satu kelompok merupakan satu keluarga inti atau keluarga terdekat. Seluruh pohon sarang yang telah diketahui pemiliknya diberi tanda sesuai dengan nama pemilik (Gambar 1.a dan b) 


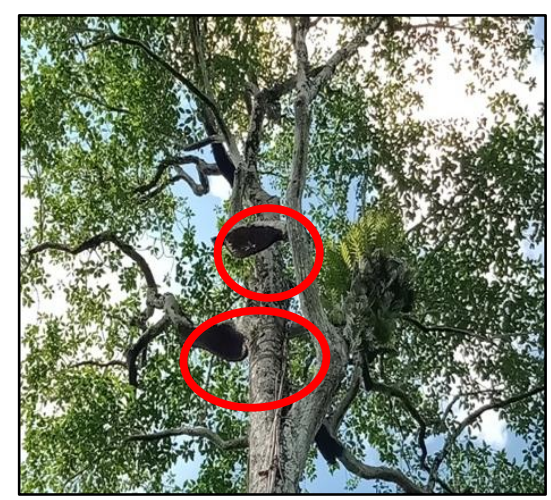

a

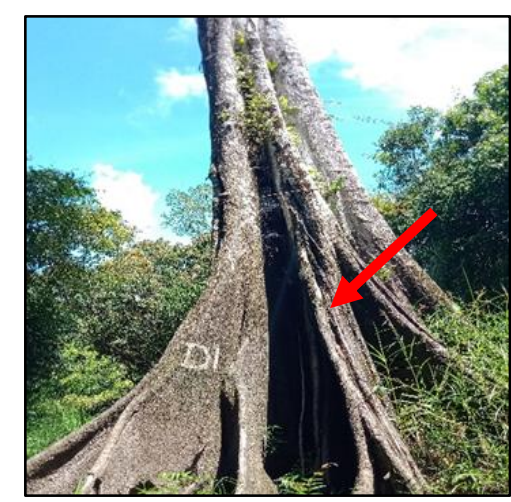

b

Gambar 1. a. Pohon Sebagai Sarang Lalau a. ( Tree As Lalau Nest ), b.Tanda Kepemilikan Pohon Lalau, b. ( Sing Of Lalau Tree Ownership )

Setiap kelompok mengelola pohon sarang lalau milik mereka dengan melakukan pembagian kerja sesuai dengan tugasnya masing-masing. Pembagian kerja dilakukan untuk mempermudah dan mempercepat proses pengolahan madu hutan, antara lain mulai dari memanjat pohon sarang lebah, mengangkat madu yang telah dipanen disimpan ditempat madu, mengiriskan madu, dan memasukan madu yang telah ditiris kedalam jerigen hingga pengemasan. Masing-masing kelompok petani madu bertanggung jawab terhadap keberadaan pohon sarang lalau, dan seluruh kelompok petani madu mempunyai kewajiban menjaga kelestarian kawasan hutan. Menurut Wanzar (2012), keberadaan kelompok petani madu hutan bertujuan untuk menjamin kualitas dan ketersedian madu serta menjaga keberadaan pohon sarang lebah dan kelestarian hutan. Menurut Mikael (2015) kelompok Muar Manyi' Desa Tunggul Boyok memiliki sikap gotong royong dalam melakukan pekerjaan, proses pemanenan madu hutan dilakukan dengan mudah dan cepat. sikap gotong royong ini telah melekat pada diri masyarakat Desa Tunggul Boyok dan merupakan kebiasaan turun temurun dari nenek moyang.

Berdasarkan hasil wawancara dan survei lapangan, terdapat lima jenis pohon yang paling sering dijadikan tempat bersarang A. dorsata (Tabel 1), dimana sebagian besar pohon yang dijadikan sebagai tempat bersarang memailiki karakteristik pohon yang tinggi, besar, mempunyai dahan kokoh dan lebar. 
Tabel 1. Jenis Pohon Sarang Lalau ( Lalau Nest Tree Type )

\begin{tabular}{llll}
\hline No & Nama local & Nama ilmiah & Famili \\
\hline 1 & Kempas & Koompassia malaccensis & Leguminosae \\
2 & Rengas & Gluta renghas & Anacardiaceae \\
3. & Tempurau & Dipterocarpus spp & Dipterocarpaceae \\
4. & Pelaik & Alstonia scholaris & Apocynaceae \\
5. & Akar libang & Connarus monocarpus & Connaraceae \\
\hline
\end{tabular}

Menurut Wanzar (2012) Sedangkan di Teso Nilo, Riau, pohon sarang madu memiliki ketinggian mencapai 50 meter atau lebih dengan diameter batang kurang lebih 2 meter disebut masyarakat Teso Nilo sebagai pohon silang. Jenis pohon silang diantaranya adalah pohon cempaka air (Artocarpus maingayi). Satu pohon silang lebah bisa membuat 100-200 sarang madu.

\section{Pemanenan Madu Lalau}

Pemanenan madu di Desa Nanga Lauk dilakukanan biasanya pada bulan Desember hingga Januari. Pemanenan madu tidak selalu tepat waktu, tergantung dari ketersediaan pakan/musim berbunga. Masyarakat Desa Nanga Lauk melakukan pembersihan pohon 1 bulan sebelum bunga bermekaran supaya lebah yang berdatangan betah dan menghasilkan madu yang banyak. Panen madu dilakukan oleh kelompok petani madu pada pohon lalau masing-masing, tidak diperbolehkan untuk merebut pohon lalau milik kelompok lain. Sarang madu dikatakan siap dipanen dapat diperkirakan (1) Umur lebah dari pertama datang ke pohon sampai dengan hari keduapuluh (2) Dilihat dari bunga yang telah habis di makan lebah (3) Koloni lebah lebih banyak bersarang di pohon.
Proses pemanenan dilakukan pada malam hari dan tidak terang bulan, karena waktu malam lebah tidak agresif dan penglihatan lebah berkurang. Teknik panen madu lalau dilakukan dengan panen lestari. Artinya saat panen, tidak diperbolehkan untuk memotong seluruh sarang, yang dipotong hanya bagian kepala sarang lebahnya saja dan harus menyisakan kurang lebih 1/3 dari sarang. Hal ini diharapkan agar lebah dapat bersarang kembali dan dapat dilakukan panen selanjutnya. Khafid (2014) menyatakan tata cara pengambilan madu hutan di Sumbawa juga menggunakan tata kelola panen lestari, dimana pencari madu tidak boleh mengambil habis sarang madu dipohonnya, namun harus menyisikan 30 persen agar lebah dapat kembali bersarang, sehingga sebulan kemudian berisi madu yang baru dan dapat dipanen kembali.

Alat panen yang digunakan harus dalam keadaan bersih agar kualitas madu yang dihasilkan baik dan sebagian besar alat panen madu berbahan stainless stell yang tidak mudah berkarat. Pengambilan sarang madu dilakukan dengan cara memanjat pohon sarang menggunakan pakau yaitu tangga yang dibuat dari kayu yang diikat pada pohon secara berurutan dari bawah hingga puncak. Setelah sampai di dekat sarang, petani madu 
mengasapkan sarang menggunakan tebaok (akar kayu jabai) yang dibakar agar lebah pergi dan petani dapat mulai memanen madu. Sarang yang telah dipanen, dimasukkan kedalam ember bersih, ditutup dan dibawa pulang untuk dilakukan pengolahan pasca panen. Menurut Sofia (2017) petani madu di Danau Sentarum masih menggunakan alat tradisional dalam pemanenan yaitu dengan menggunakan kain kasa, akar pohon jabai, untuk pembuatan sempun (alat pengasapan) dan menggunakan jerigen dengan berbagai ukuran tanpa ada label khusus.

\section{Pengolahan Hasil Pemanenan}

Hasil madu yang telah dipanen langsung diolah oleh petani dirumah, apabila tidak langsung diolah dan kondisi ember dalam terbuka kemungkinan lebah akan menyerang sarang yang telah dipanen. Alat yang harus disiapkan untuk proses pengelolaan diantaranya adalah kain kasa, sarung tangan karet, pisau stanlees, ember, corong dan juga jerigen. Proses pengolahan madu lalau menggunakan sistem tiris. Proses tiris bertujuan untuk memisahkan sarang dengan madunya. Saat proses penirisan harus menggunakan sarung tangan agar kebersihan madu terjaga. Masyarakat Desa Nanga Lauk melarang memeras madu, agar madu yang dihasilkan tidak berubah rasa dan mendapatkan madu yang bersih tanpa ampas serta mengurangi kadar air. Petani madu ada yang melakukan proses penyaringan satu kali dan dua kali. Penyaringan satu kali hanya dilakukan mennggunakan kain kasa, sedangkan penyaringan dua kali di saring menggunakan waring selanjutnya disaring lagi dengan menggunakan kain kasa. Setelah disaring, proses selanjutnya adalah memasukan madu yang telah di tiriskan ke dalam jerigen dan siap di pasarkan. Sofia (2017) menyatakan para petani madu di Danau Sentarum juga melakukan proses pengolahan dengan cara penirisan. Hal ini dilakukan selain untuk menghasilkan madu yang bersih juga untuk mengurangi kadar air. Karena jika menggunakan sistim peras, selain madu yang dihasilkan banyak mengandung ampas, air yang masih ada di dalam sarang akan ikut larut, sehingga kadar air madu menjadi bertambah.

\section{Pengemasan}

Jumlah produksi madu lalau yang ada di Desa Nanga Lauk masih cukup banyak, dilihat jumlah madu yang dihasilkan. Saat panen, satu sarang bisa menghasilkan madu sebanyak $5-20 \mathrm{~kg}$ tiap panen, dimana satu pohon lalau bisa memiliki hingga 100 sarang, dengan rata-rata panen $100 \mathrm{~kg}$ - $400 \mathrm{~kg}$ pada satu pohon. Pada satu tahun terakhir (20182019), jumlah produksi madu Desa Nanga Lauk dapat mencapai 7 ton , dimana masing-masing petani dapat menghasilkan $900 \mathrm{~kg}-1.000 \mathrm{~kg}$ madu. Madu yang dihasilkan tergantung pada musim bunga yang mekar dan jumlah pohon sarang yang dimiliki.

Madu lalau di Desa Nanga Lauk dikemas menggunakan jerigen berbagai ukuran tanpa ada label khusus yang digunakan untuk tanda pengenal produksi, karena Desa Nanga Lauk tidak 
memiliki pendampinga khusus dalam proses produksi dan pemasaran. Danger (1992) menjelaskan, bahwa dengan adanya pembungkus atau kemasan, diharapkan produk terhindar dari pengotoran, penyusutan atau berbagi macam faktor yang menyebabkan penurunan kualitas produk.

\section{Pemasaran}

Pemasaran madu lalau dilakukan secara bebas dengan sistem curah dan dikemas dalam jerigen tanpa label. Menurut petani madu penjualan dengan sistim curah lebih menguntungkan, hal ini dikarenakan pembeli lebih memilih membeli dalam jumlah banyak. Para petani ada yang menjual langsung dan ada juga pelanggan yang datang mengambil ke petani. Harga madu per kilogram dijual dengan kisaran Rp. 150.000 - Rp. 200.000,-, tergantung jumlah madu yang dihasilkan tiap musim panen. Saat musim panen raya, bisanya harga madu menjadi lebih murah, namun saat musim paceklik (hanya sedikit bunga yang mekar), harga madu menjadi lebih tinggi. Menurut Julmansyah (2010) usaha madu hutan perlu lebih ditata dan kelembagaannya diorganisir untuk menghasilkan kualitas madu yang memenuhi standar persyaratan tertentu.

Selain itu, untuk menjamin kelestarian pohon sarang lebah yang menjadi sumber penghasil madu hutan.

\section{KESIMPULAN}

Berdasarkan hasil penelitian yang telah dilaksanakan, dapat disimpulkan bahwa proses pengelolaan madu lalau yang dilakukan oleh Masyarakat Desa Nanga Lauk masih dilakukan secara tradisional, turun temurun dan berkelompok, yang dimulai dari pemeliharaan kawasan hutan, penentuan kepemilikan pohon sarang, proses pemanenan madu hutan, pengolahan hasil panen, pengemasan dan pemasaran.

\section{SARAN}

Berdasarkan hasil penelitian yang telah dilaksanakan, dapat di sarankan sebagai berikut bahwa perlu kesadaran masyarakat petani madu dalam melestarikan kearifan lokal dengan tidak membakar hutan atau membuka ladang sembarangan, tidak menebang pohon sembarangan, guna sebagai upaya pelestarian habitat lebah madu dan produksi madu hutan.

\section{DAFTAR PUSTAKA}

Danger, E.P. 1992. Memilih Warna Kemasan: Pedoman Aplikasi. Jakarta : PT Pustaka Binaman Pressindo.

Julmansyah 2010. Madu Hutan Menekan Deforestasi. Jalan Lain Konservasi DAS dan Adaptasi Perubahan Iklim. Jaringan Madu Hutan Sumbawa (JMHS). Desa Batu dulang, Kecamatan Batu lanteh : Pondonk Madu Rakyat.

Khafid S.2014. Melestarikan Madu Sumbawa. Mataram : Tempo

Mikael, Iskandar, Hardiyansyah G, 2015. Kearifan lokal masyarakat Desa Tunggul Boyok dalam pengelolaan madu alam di Kecamatan Bonti Kabupaten Sanggau. Jurnal Hutan Lestari 3 (1) $: 80-87$

Nawawi, H. 2005. Penelitian Terapan. Yogyakarta : Gajah Mada University Press 
JURNAL HUTAN LESTARI (2021)

Vol. 9 (1): 37 - 44

Sofia, Roslinda E, Zainal S, 2017. Pengelolaan madu hutan berbasis kearifan lokal masyarakat di Desa Semalah dan Desa Melemba Sentarum Kabupaten Kapuas Hulu. Jurnal Hutan Lestari 5 (2) : 209 - 217 kawasan Danau

Wanzar. A . 2012. Manual Panduan Pengelolaan Madu Hutan Tesso Nilo Secara Lestari Melalui Pendekatan Sistem Kontrol Internal (ICS)/edisi kedua. Riau : WWF-Forum Masyarakat Tesso Nilo, Yayasan Tesso Nilo, Tesso Nilo. TFCA Sumatra : WWFIndonesia dan Asosiasi Petani Madu Hutan. 